\title{
Selection of ion sensor operating parameters in quasi-static conditions
}

Evaluating combustion quality using sensors that allow continuous assessment of the process is one of the modern methods of engine sensory diagnostics. The proper calibration of such systems is a task that requires many studies to determine the conditions and quantities affecting the process. The analysis of significance of quantities related to the ionization signal was carried out in the article. The magnitude of the voltage generating the electric field, the type of spark plug used, the distance of the spark plug electrodes and the dynamic factor - spark plug operating temperature - were all tested. The tests were carried out using a CNG burner (with an excess air ratio of $\lambda=1$ ) and four spark plugs. As a result of the ionization signal research, the following relationships were obtained: regarding the impact of the sensor position on the amount of generated voltage (the smaller the distance the greater the value of the signal), the effect of temperature on the sensor resistance (non-linear relationship: increase in temperature decreases resistance, with $R^{2}=0.9997$ ) effect of system voltage on the ionization signal (linear relationship: voltage increase increases the ionization current signal with a determination coefficient of $R^{2}=0.9803$ ). In addition, it was found that using an iridium electrode candle had the best effects on the ionization current, regardless of the electrode's geometrical parameters.

Key words: ionization sensor, engine control, combustion process diagnostics

\section{Introduction}

The ionization signal is used in many engine applications. Popular brands such as Mazda, Saab, BMW and Harley-Davidson [4] successfully use knock detection systems based on the ionization signal. The efficiency and fast response time of such a system has also been successfully used in Formula 1 engines [9]. There are also other, less popular solutions, that use the phenomenon of ion formation in the cylinder to measure EGR content [8], determine the quality indicators of the combustion process [2] or control the operation of the HCCI engine [7].

The nature and amplitude of the ionization signal is a derivative of many factors, both static and dynamic, i.e. variable over time. Determining their effect on the signal allows the use of the ionization sensor as an advanced diagnostic tool in modern internal combustion engines, and thus allows to improve the engine's operating indicators and reduce harmful exhaust emissions.

One of the most important factors varying in time is the density of ions and free electrons between the spark plug electrodes that allow a free flow of current. The more ions and free electrons are available, the more ionization current could potentially flow in the circuit. The presence of ions in an internal combustion engine results mainly from the phenomenon of chemical and thermal ionization of gas [4]. Both phenomena strongly depend on the process temperature $[6$, 11]. The degree of gas ionization by radiation depends on the temperature as described by the Saha's formula [5]:

$$
\frac{\mathrm{N}_{\mathrm{j}} \mathrm{N}_{\mathrm{e}}}{\mathrm{N}_{\mathrm{n}}}=2 \frac{\mathrm{u}_{1}}{\mathrm{u}_{0}} \frac{(2 \pi \mathrm{mkT})^{\frac{3}{2}}}{\mathrm{~h}^{3}} \mathrm{e}^{-\mathrm{E}_{0} / \mathrm{kT}}
$$

where: $\mathrm{N}_{\mathrm{j}}$ - ion concentration, $\mathrm{N}_{\mathrm{e}}$ - free electron concentration, $\mathrm{N}_{\mathrm{n}}-$ non-ionized atoms concentration, $\mathrm{m}$ - electron mass, $\mathrm{k}$-Boltzmann's constant, $\mathrm{h}$ - Planck's constant, $\mathrm{T}$ gas temperature, $\mathrm{E}_{0}$ - ionization energy, $\mathrm{u}_{\mathrm{o}}$ and $\mathrm{u}_{1}-$ so-called partition functions specific to a given chemical element.
Another factor affecting ion density is the type of fuel used, as well as its octane number [10]. Eriksson [3] indicates that the so-called chemical phase curve rise is related to the composition of the air-fuel mixture.

The current flowing through the sensor also depends on the design of the electrical system. While the resistance of the sensor itself can be classified as variable over time (due to the change in sensor temperature, and thus its material resistance), the other elements of the measuring system can be characterized as static.

The characteristics of the sensor itself, i.e. the spark plug, can be named as one of the static factors affecting the ionization signal. The structure of the electrodes, their number, materials used and even the heat value of the spark plug [1] have a direct impact on the signal amplitude. Similarly, the electrical parameters of the system, such as the intensity of the electric field generated by the high voltage system, as well as the measuring resistance itself contribute to the current flow parameter $[3,5]$.

There are a number of factors conditioning the formation of the ionization signal: the presence of soot on the spark plug electrodes, air humidity, the rate of ion formation [3], and others.

The aim of this article is to try to select the ionization sensor operating parameters in conditions close to static, so that it is possible to determine the interacting factors and obtain the parameters of a universal measuring system that allows repeatable measurements of the ionization signal and their unambiguous interpretation in the future.

\section{Method}

\subsection{Test stand}

A Teclu laboratory gas burner was used to achieve measurement conditions similar to static (Fig. 1). The fuel burned in the burner provided a stable, constant source of 
ions and free electrons generated in the flame as a result of the thermal and chemical ionization process.

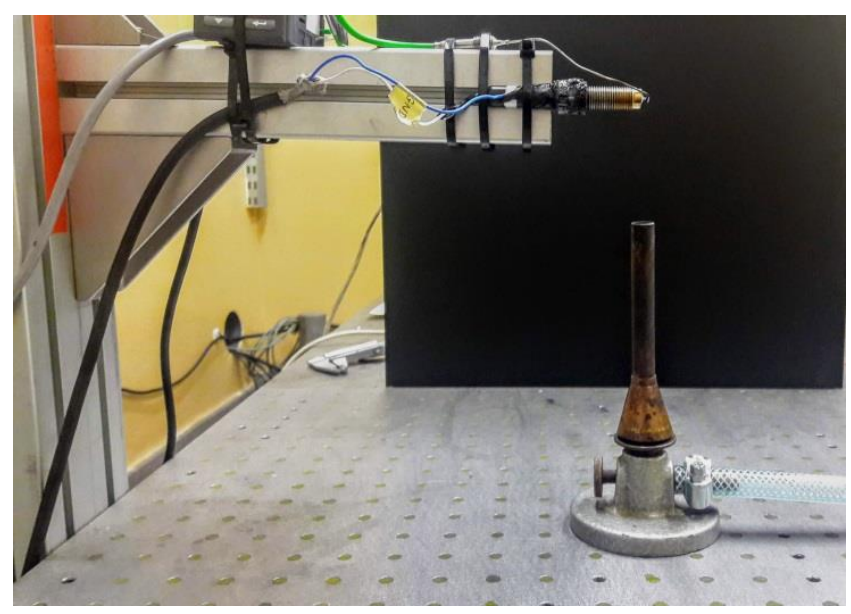

Fig. 1. Teclu gas burner test stand

The measuring element used was the spark plug typically used in spark-ignition internal combustion engines. The spark plug was attached to a structure that allowed changing its height. A K-type thermocouple with a maximum measuring range of $1100^{\circ} \mathrm{C}$ was used to determine the operating conditions of the ionization sensor, whose tip with a diameter of $1 \mathrm{~mm}$ was located near the measuring electrodes (Fig. 2).

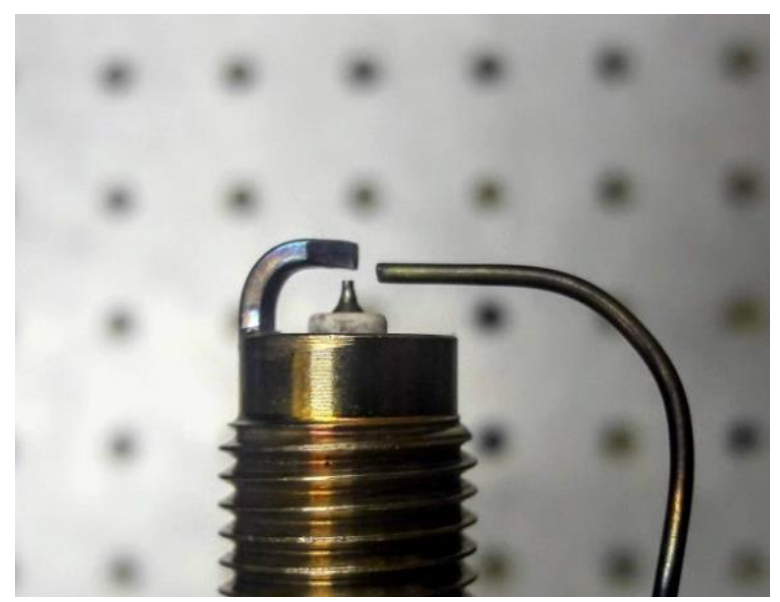

Fig. 2. Measurement of the ionization sensor operating temperature

The amount of gas supplied was determined using a Bronkhorst 111B flow meter. In order to determine the air excess coefficient $\lambda$, the burner settings were calibrated using an exhaust gas oxygen sensor - Bosch LSU 4.9.

Diagram of the ionization current measuring circuit is shown in Figure 3. The source of the electric field was a DC power supply with an adjustable voltage range of 50$388 \mathrm{~V}$. The direct measurement element was a resistor with a variable resistance setting in the range of $0-1.14 \mathrm{M} \Omega$. According to Ohm's law, the ionization current flowing in the circuit generated a proportional difference in potential across the resistor. The ionization voltage thus obtained along with the other signals (temperature, gas mass flow) was recorded by the AVL IndiCom data acquisition system.

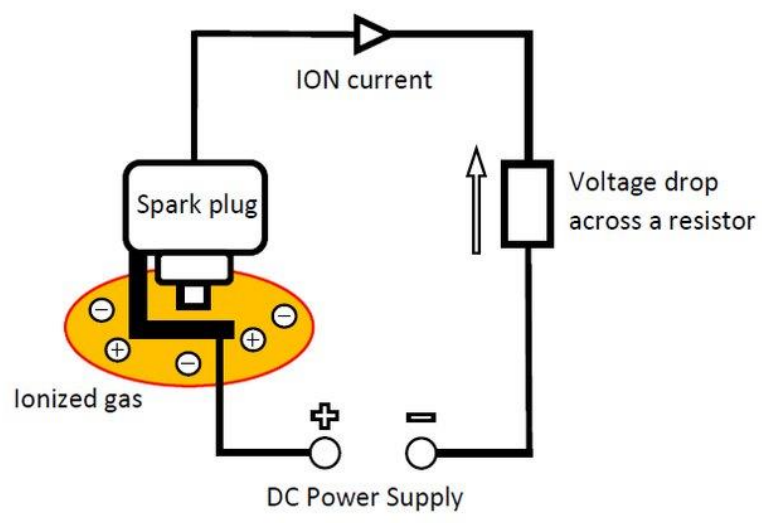

Fig. 3. Electric schematic of the measurement system [4]

\subsection{Measurement points}

The adopted research strategy was aimed at determining the impact of the main static factors on the signal, so that in the future it is possible to clearly interpret the results regardless of the research conditions.

The main static factors were determined in the article as:

- voltage generating an electric field,

- spark plug type used,

- spark plug electrode distance.

As well as the dynamic factor:

- the operating temperature of the spark plug affecting the resistance of the system.

The parameters of the burner and the measuring system used to determine the influence of static factors are presented in Table 1. The characteristics of the spark plugs used are shown in Table 2.

Table 1. Parameters of the burner and the ionization sensor

\begin{tabular}{|l|c|c|c|}
\hline$\lambda$ & 1 & 1 & 1 \\
\hline Q_CNG [g/h] & 31.6 & 31.6 & 31.6 \\
\hline Spark plug number & 1 & $1-4$ & 2 \\
\hline System voltage $[\mathrm{V}]$ & $50-388$ & 200 & 200 \\
\hline Resistance $[\mathrm{M} \Omega]$ & 1.142 & 1.143 & 1.143 \\
\hline Measurement height $[\mathrm{mm}]$ & 8 & 8 & 8 \\
\hline
\end{tabular}

Table 2. Parameters of the spark plugs used

\begin{tabular}{|l|c|c|c|c|}
\hline $\begin{array}{l}\text { Spark plug } \\
\text { designation }\end{array}$ & $\begin{array}{c}\text { NGK } \\
\text { T20379G }\end{array}$ & $\begin{array}{c}\text { Denso } \\
\text { XE20HR-U9 }\end{array}$ & $\begin{array}{c}\text { Denso } \\
\text { X27ETR }\end{array}$ & $\begin{array}{c}\text { Denso } \\
\text { IXEH22TT }\end{array}$ \\
\hline Spark plug number & 1 & 2 & 3 & 4 \\
\hline Resistance [k $\Omega]$ & 1.65 & 4.72 & 6.33 & 5.71 \\
\hline $\begin{array}{l}\text { Electrodes separa- } \\
\text { tion [mm] }\end{array}$ & 0.45 & $0.4 ; 0.8 ; 1.2$ & $0.7 \times 2$ & 0.95 \\
\hline $\begin{array}{l}\text { Electrode diameter } \\
\text { [mm] }\end{array}$ & 0.7 & 2.1 & 2.2 & 0.5 \\
\hline Electrode material & iridium & nickel & nickel & iridium \\
\hline
\end{tabular}

\section{Results}

\subsection{Impact of sensor location on the amount of genera- ted voltage}

Various sensor positions relative to the burner ranging from 0.8 to $11 \mathrm{~cm}$ distance were analyzed. The criterion for choosing the measuring point was a stable and high concentration of ions and free electrons in the flame (Fig. 4). Ini- 
tial, experimental recognition allowed the determination of the optimal measuring point (position $0.8 \mathrm{~cm}$ above the burner), which was used in subsequent research. It was observed that as the distance from the burner increased, an ionization signal with a lower value and less stability was obtained.
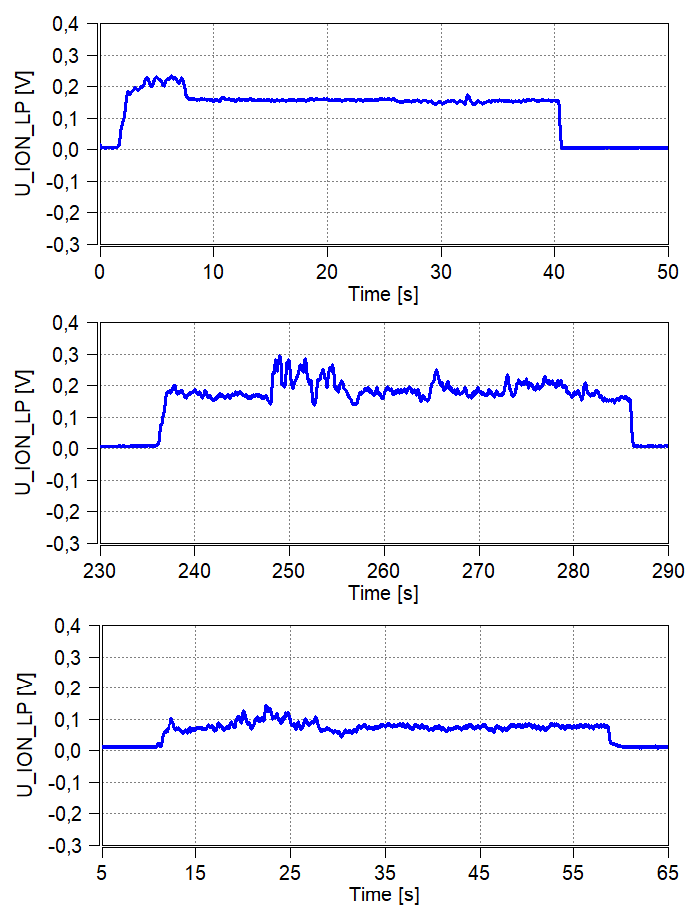

Fig. 4. Ionization voltage signal waveform; measuring points, from the top: 1, 3 and $8 \mathrm{~cm}$ above the burner (spark plug No. 2)

\subsection{Impact of temperature on the sensor resistance}

As a result of the combustion process in the cylinder, the temperature of the engine components increases, which includes the spark plug, which also functions as an ionization current sensor. As a result of this phenomenon, the spark plug resistance values in the temperature range 0 $175^{\circ} \mathrm{C}$ were determined in order to determine the possible influence of the sensor temperature on the size and nature of the ionization current signal. An increase in the resistance value of one of the elements causes a change in the electrical parameters of the entire system. Figure 5 shows the change in resistance of spark plug number 1 as a function of its temperature. Based on the relationship $R=f(T)$, the regression equation was determined, describing the value of resistance $R$ as a function of the spark plug temperature $\mathrm{T}$ :

$$
\mathrm{R}=2 * 10^{-5} \mathrm{~T}^{2}-0.0078 \mathrm{~T}+1.8544
$$

Changing the temperature from 0 to $175^{\circ} \mathrm{C}$ causes the resistance of spark plug number 1 to decrease by $43 \%$. Assuming that the average value of current I flowing during engine operation is about $6 \mu \mathrm{A}$ (typical value for an SI engine powered with natural gas) and the voltage value $U$ of the system is about $300 \mathrm{~V}$ (typical value for ionization sensors), then as a result of Ohm's law the theoretical value of system resistance can be obtained:

$$
\mathrm{R}=\frac{\mathrm{U}}{\mathrm{I}}=\frac{300 \mathrm{~V}}{6 \mu \mathrm{A}}=50 \mathrm{M} \Omega
$$

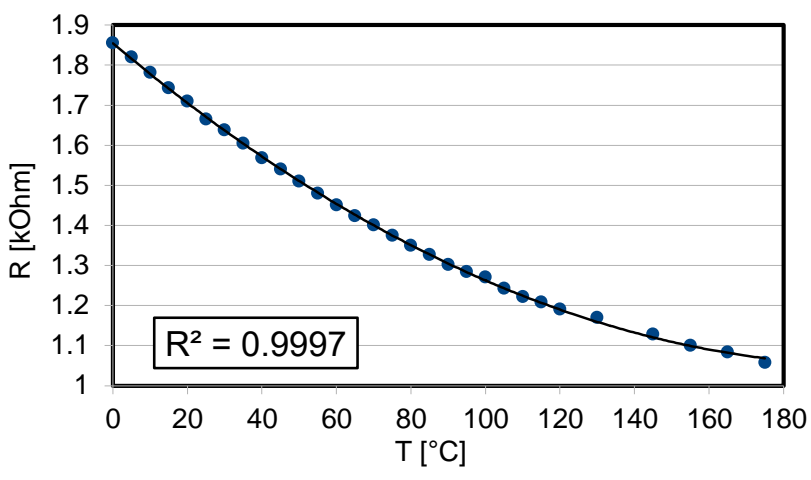

Fig. 5. Impact of sensor temperature on the value of its resistance (spark plug No. 1)

So (in this particular case), a change in the resistance of one of the circuit components, which is the spark plug (No. 1) by $43 \%$, causes a change in the resistance of a typical measuring system by 0.0016 . Thus the effect of the sensor temperature on the ionization signal was concluded to be small, or even negligible; however, this applies to the circuit used by the authors.

\subsection{Impact of system voltage on the ionization signal}

According to previous studies, the sensor was centered in the flame at a height of $8 \mathrm{~mm}$ above the burner. The voltage value was increased in increments of $50 \mathrm{~V}$ until it reached its maximum (Fig. 6). Figure 7 shows the measurement results of the ionization current relative to the system voltage.
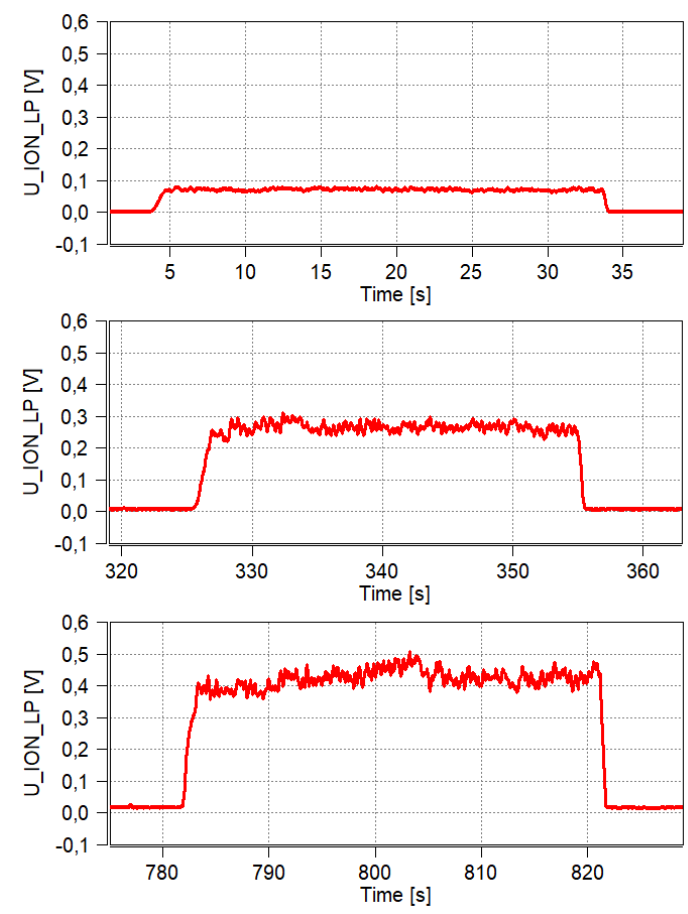

Fig. 6. Ionization waveforms with system voltage of (from the top): $50 \mathrm{~V}$, $200 \mathrm{~V}$ and $388 \mathrm{~V}$ (spark plug No. 1)

As a result of the voltage increase, an increase in the ionization current was observed, which is directly related to the increase in the electric field intensity between the spark plug electrodes. In addition, it is potentially possible to 
further increase the value of the flowing ionization current by increasing the system voltage. Thus the so-called saturation current can be reached, after which all the ions formed around the spark plug electrodes will be captured by the sensor.

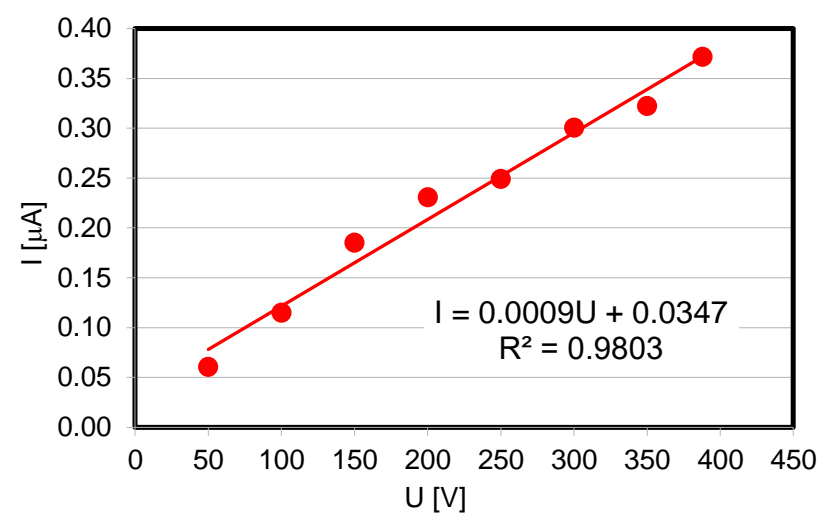

Fig. 7. Impact of the measuring system voltage on the ionization current value (spark plug No. 1)

\subsection{Impact of the selected spark plug type}

In order to determine their effect on the ionization current signal the characteristics of four types of spark plugs were presented in Table 2. In addition, the influence of the electrodes separation distance on the received signal was examined for the spark plug number 2. These distances were: $0.4,0.8$ and $1.2 \mathrm{~mm}$. Each of the spark plugs was located centrally in the flame of the burner at a height of 8 $\mathrm{mm}$. The value of the system voltage was $200 \mathrm{~V}$, and the excess air coefficient $\lambda$ was set to a value of 1 . The waveforms of the (selected) measured signals are shown in Fig. 8 and the collective results in Table 3 .
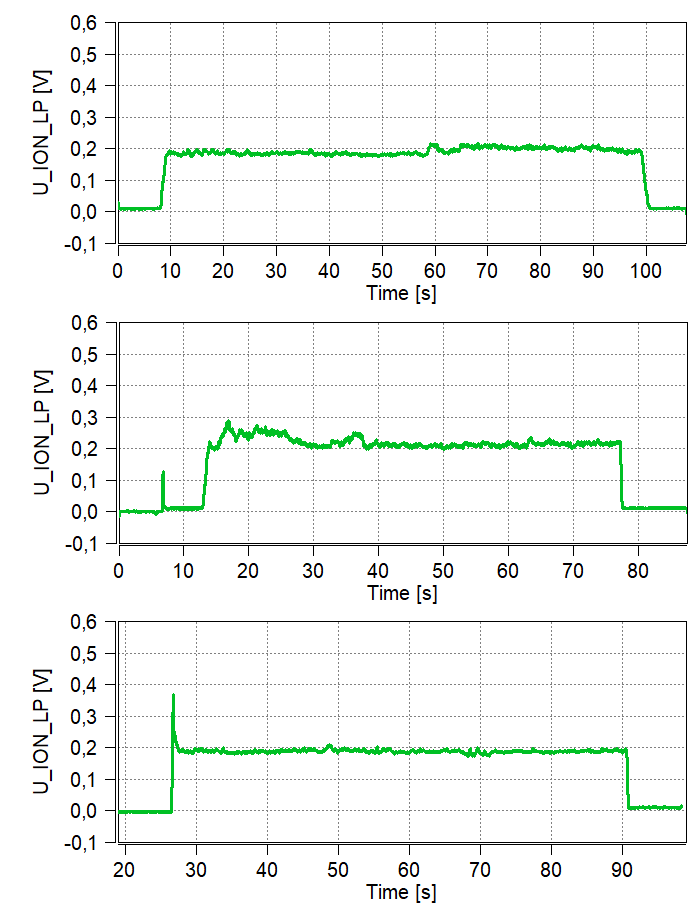

Fig. 8. Ionization signal waveforms using spark plug 2 with equal spacing (from the top): $0.4,0.8$ and $1.2 \mathrm{~mm}$
Table 3. Ionization signal measurement results for selected spark plugs

\begin{tabular}{|c|c|c|c|}
\hline $\begin{array}{c}\text { Spark plug } \\
\text { number }\end{array}$ & $\begin{array}{c}\text { Electrodes } \\
\text { separation }[\mathrm{mm}]\end{array}$ & $\begin{array}{c}\text { Mean ionization } \\
\text { voltage [V] }\end{array}$ & $\begin{array}{c}\text { Mean ionization } \\
\text { current }[\mu \mathrm{A}]\end{array}$ \\
\hline 1 & 0.45 & 0.221 & 0.193 \\
\hline 2 & 0.4 & 0.201 & 0.176 \\
\hline 2 & 0.8 & 0.214 & 0.187 \\
\hline 2 & 1.2 & 0.186 & 0.163 \\
\hline 3 & $0.7 \times 2$ & 0.206 & 0.180 \\
\hline 4 & 0.95 & 0.222 & 0.194 \\
\hline
\end{tabular}

The average ionization current values indicate that spark plug 4 has the highest capacity to attract ions and electrons from the flame, and the smallest spark plug 2 with the electrode separation distance equal to $1.2 \mathrm{~mm}$. The sensor No. 4 electrodes are made of iridium, are $0.95 \mathrm{~mm}$ apart and the diameter of the central electrode is $0.5 \mathrm{~mm}$. Spark plug 2 has nickel electrodes, the distance between them is $1.2 \mathrm{~mm}$, and the diameter of the positive electrode is $2.1 \mathrm{~mm}$.

The experiment has also shown that the position of the sensor relative to the flame is important in relation to the ionization current signal received. Spark plug No. 2 was located in the center of the flame, but during the second test the current value was $3 \%$ higher than in the first. In order to accurately identify the impact of the spark plug used, it is necessary to repeat the tests using an ionization sensor located in the internal combustion engine or to increase the precision of the spark plug positioning in the flame of the burner.

\section{Conclusions}

Based on the research and analysis, a large impact on the ionization current was found for the spark plug separation distance, sensor temperature, system voltage and type of spark plug used.

The following detailed conclusions have been drawn:

a) a change in the distance between the spark plug and the energy source (burner) significantly changes the generated ionization current values. The optimal value was set at $8 \mathrm{~mm}$;

b) the operating temperature of the spark plug has the opposite effect (but not linearly) on its resistance. Resulting in the relation: $\mathrm{R}=2 \cdot 10^{-5} \cdot \mathrm{T}^{2}-0.0078 \cdot \mathrm{T}+$ +1.8544 , with the coefficient of determination equal to $\mathrm{R}^{2}=0.9997$

c) the relation between the system voltage and the ionization signal is proportional to the value of this voltage: this can be denoted as: $\mathrm{I}=-9 \cdot 10^{-7} \cdot \mathrm{U}^{2}+0.0013 \cdot \mathrm{U}+$ +0.0035 (where $\mathrm{R}^{2}=0.9803$ ), which means that every voltage change of $50 \mathrm{~V}$ changes the ionization current by about $0.045 \mathrm{~A}$;

d) a spark plug with an iridium electrode provided the most favorable ionization current results, independently from the distance between the electrodes.

The conducted tests confirmed the need for further research related to the ionization signal, which may soon become a diagnostic signal allowing the assessment of subsequent aspects of the combustion process (development of the flame front, its propagation speed or other parameters). 


\section{Nomenclature}

I ionization current

$\mathrm{U}$ voltage

$\mathrm{N}$ concentration

$\mathrm{R}$ resistance

$\lambda$ air excess ratio

\section{Bibliography}

[1] DANIELS, C.F. Mass fraction burned and pressure estimation through spark plug ion sensing. Patent US6089077A (2000).

[2] DEV, S., SANDHU, N.S., IVES, M. et al. Ion current measurement of diluted combustion using a multielectrode spark plug. SAE Technical Paper. 2018-011134. DOI: $10.4271 / 2018-01-1134$

[3] ERIKSSON, L. Methods for ionization current interpretation to be used in ignition control. Diploma Thesis 1995, Linkoping.

[4] FIEDKIEWICZ, Ł., PIELECHA, I., WISŁOCKI, K. Use of the gas ionization signal for combustion process diagnostics in the cylinder of a spark ignition engine. Combustion Engines. 2017, 171(4), 196-200. DOI: 10.19206/CE-2017-433

[5] FRANKE, A. Characterization of an electrical sensor for combustion diagnostics. Doctoral Thesis 2002, Lund.

[6] GURBUZ, H. Experimental evaluation of combustion parameters with ion-current sensor integrated to fast response thermocouple in SI engine. Journal of Energy Engineering. 2016, 143(2), 04016046. DOI: 10.1061/ (ASCE)EY.1943-7897.0000401
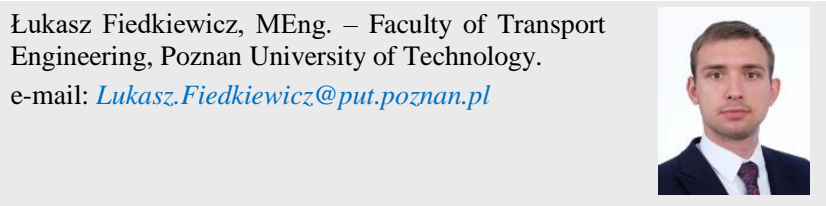

[7] HUNICZ, J., FILIPEK, P., SOBIESIAK, A. Application of ion current measurement to identification of combustion parameters in a homogeneous charge compression ignition engine. Metrology and Measurement Systems. 2018, 25(1), 223-234. DOI: 10.24425/118171

[8] KUSUHARA, T., SHINKAI, T., YOSHIDA, K. et al. Development on internal EGR feedback control based on ion current. SAE Technical Paper. 2017-01-0793. DOI: $10.4271 / 2017-01-0793$

[9] SHIMASAKI, Y., MAKI, H., SAKAGUCHI, J. et al. Study on combustion monitoring system for formula one engines using ionic current measurement. SAE Technical Paper. 2004; 2004-01-1921. DOI: 10.4271/ 2004-01-1921

[10] VRESSNER, A., HULTQVIST, A., TUNESTAL, P. et al. Fuel effects on ion current in an HCCI engine. SAE Technical Paper 2005-01-2093.

[11] ZHONGQUAN, G., XIAOMIN, W., MAN, CH. et al. The relationship between ion current and temperature at the electrode gap. Applied Thermal Engineering. 2012, 33-34(1), 15-23. DOI: 10.1016/j.applthermaleng.2011.07.014

Prof. Ireneusz Pielecha, DSc., DEng. - Faculty of Transport Engineering, Poznan University of Technology.

e-mail: Ireneusz.Pielecha@put.poznan.pl

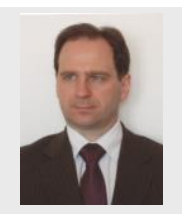

